\title{
The Impact of Contingency Factors on the Balanced Scorecard Adoption: Evidence from Algeria
}

http://doi.org/10.21272/bel.5(4).32-47.2021

Mehdi Bouchetara, ORCID: https://orcid.org/0000-0001-9826-8985

Dr., Assistant Professor, Higher National School of Management, Algeria

Sara Aicha Amrani, ORCID: https://orcid.org/0000-0001-5601-8427

Master student, Higher National School of Management, Algeria

Messaoud Zerouti, ORCID: https://orcid.org/0000-0001-9802-5334

Dr., Assistant, Professor, Higher National School of Management, Algeria

Sidi Mohammed Bouchenak Khelladi, ORCID: https://orcid.org/0000-0002-4908-2807

Dr., Professor, Higher National School of Management, Algeria

Nabil Mehddeb, ORCID: https://orcid.org/0000-0002-0336-6441

Dr., Assistant Professor, Higher National School of Management, Algeria

\begin{abstract}
This article aims to analyse the existence of significant relationships between some contingency factors and the degree of adoption of the balanced scorecard. A quantitative study, based on a survey, is conducted among 186 individuals, belonging to different Algerian enterprises, from different sectors. Only 57 responses were obtained, that 43 were complete and usable. Otherwise, we obtained a response rate of $23.12 \%$. The results indicate that only three contingency factors (age, differentiation strategy and competition intensity) are found to be significantly associated with the degree of use of the balanced scorecard indicators. Thus, we conclude that the adoption of the balanced scorecard increases with the rivalry of firms in the markets, with the degree of diversity of their products/services and that older and more mature firm are more likely to use this tool. Despite this study's limitations, the main findings have potential implications for future research, particularly for researchers wishing to test the diversity in the use of the balanced scorecard across different industries and to explore its advantages and disadvantages. Our model is limited by its exclusion of the effects of other important contingency factors, such as organisational culture, corporate social responsibility, industry, computerisation and others. However, limiting ourselves to a one country allows us to control for the effects of local management practices. We provide evidence of associations rather than drawing conclusions about causality. Another limitation is due to the low representativeness of the sample which may generate a risk of bias.
\end{abstract}

Keywords: Performance Measurement System, Balanced Scorecard, Contingency Factors, Management Control, Economic Enterprises.

JEL Classification: M12, M21, P17.

Cite as: Bouchetara, M., Amrani, S.A., Zerouti, M., Bouchenak, K.S.M., Mehddeb, N. (2021). The Impact of Contingency Factors on the Balanced Scorecard Adoption: Evidence from Algeria. Business Ethics and Leadership, 5(4), 32-47. http://doi.org/10.21272/bel.5(4).32-47.2021.

Received: 15 October 2021

Accepted: 05 December 2021

Published: 16 December 2021

Copyright: (C) 2021 by the author. Licensee Sumy State University, Ukraine. This article is an open access article distributed under the terms and conditions of the Creative Commons Attribution (CC BY) license (https://creativecommons.org/licenses/by/4.0/).

\section{Introduction}

Uncertainty, competition intensity (Rherib, El Amili, \& Baba El Khourchi, 2021), fast technological evolutions, and shortened product life cycles characterize today's environment (Nimpa \& Teulon, 2018). These environmental characteristics have led to a crisis in the management control field. Corporate management control's traditional performance measurement practices are criticized for their lack of effectiveness (Rherib, El Amili, \& Baba El Khourchi, 2021). To remedy this, in 1992, Kaplan and Norton proposed a new 
performance measurement tool called the Balanced Scorecard (Kaplan \& Norton, 1996; Moura, 2020). The focus on knowledge and other intangible assets emphasizes evaluating company performance based on multidimensional and diversified indicators rather than only by financial indicators (Nimpa \& Teulon, 2018). In practice, and to adapt to an increasingly complex internal and external environment, comply with an organization's internal development needs, and achieve the organization's goals, business leaders are paying increasing attention to strategic issues ( $\mathrm{Li}, \mathrm{An}, \& \mathrm{Liu}, 2021)$. A balanced scorecard is a tool that addresses this potential. Despite the development of other systems and models, the continuous development of the balanced scorecard concept from a simple strategy assessment and performance measurement tool to a strategic management system and then, to a sustainable measurement system is widely discussed, evaluated and applied over the last three decades (Moura, 2020). This topic is gaining momentum in scientific research approaching this tool from different angles (Dudic, Dudic, Gregus, Novackova, \& Djakovic, 2020).

This article aims to analyse the existence of significant relationships between some contingency factors and the degree of adoption of the balanced scorecard. A quantitative study, based on a survey, is conducted among 186 individuals, belonging to different Algerian enterprises, from different sectors. Only 57 responses were obtained, that 43 were complete and usable. Otherwise, we obtained a response rate of $23.12 \%$. Moreover, it gives thoughtful basis to CFOs and controllers on how effectively meet the information needs of all stakeholders of the company (Bouamama, Basly, \& Zian, 2021). The structural or organizational contingency theory principles are followed (Bouamama, Basly, \& Zian, 2021). The factors related to this type of contingency refer to the fundamental characteristics that define an enterprise's internal and external contexts (Bouamama, Basly, \& Zian, 2021; Hassan, Nordin, \& Azamin, 2021). The research model is tested on a sample of 43 companies (out of 186 who were contacted) from different Algerian companies. The quantitative study results show that financial managers and controllers of these companies use the four dimensions of the balanced scorecard at different frequencies. They mostly use financial indicators. Also, their dashboards are moderately balanced. Moreover, only three factors are found to have a significant impact on the adoption of balanced scorecards. These factors are age, differentiation strategy, and competitive intensity.

A considerable number of studies approach the impact of the contingency factors on the balancing of dashboards, foreign or national. In the Algerian context, this phenomenon is very often studied by applying the structural equations, the PLS (Partial Least Squares), and the Boostrap methods (Ali-Belhadj \& Benhabib, 2018; Alibelhadj, 2019; Hassani \& Derahmoune, 2020). Therefore, this research is interested in identifying the causal links between the balanced scorecard four dimensions and the factors impacting the multi-dimension and diversity of performance measurement systems. This article is structured as follows. Section two presents a literature review on the balanced scorecard BSC approach and develops the research hypotheses. Section three describes the data and the method followed. Then, Section four presents the research results and Section five offers their discussion. Finally, the conclusion which is presented in Section 6.

\section{Literature Review}

2.1. Balanced Scorecard Approach. The balanced scorecard is primarily developed as a performance measurement tool (Kaplan \& Norton, 1992; Mamabolo \& Kerrin , 2020; Costantini, Landi, \& Bonazzi, 2020). This tool suggests four metrics; financial, customer performance, internal processes, learning and growth (Kaplan \& Norton, 1992; Kaplan \& Norton, 1993; Kaplan \& Norton, 2007; Kaplan R., 2010; Sharma \& Sharma, 2020; Rherib, El Amili, \& Baba El Khourchi, 2021). The balanced scorecard provides executives with a comprehensive framework that translates a company's strategic objectives into a consistent set of performance measures (Kaplan \& Norton, 1992; Kaplan \& Norton, 1993). The diverse and balanced use of financial and non-financial measures helps to strengthen the link between strategy and operations (Bouamama, Basly, \& Zian, 2021). Being increasingly associated with strategic planning and implementation, the BSC serves as a management framework capable of identifying and exploiting key value drivers that companies can leverage to optimize their strategies (Costantini, Landi, \& Bonazzi, 2020). Thus, it has become a comprehensive strategic management system (Kaplan \& Norton, 2001; Kaplan \& Norton, 2007; Costantini, Landi, \& Bonazzi, 2020).

The organization's measurement system strongly affects the behaviour of managers and employees (Kaplan \& Norton, 1992; Kaplan \& Norton, 2001). The balanced scorecard is considered a non-human actor that influences human actors and brings specific benefits from long-term use because of the different roles this tool plays (Bescos, Deville, \& Foulquier, 2020). Despite the likely technical hurdles and difficulties associated with implementing the balanced scorecard, human resource management is not the least of the issues explaining the success of the balanced scorecard approach (Bouamama, Basly, \& Zian, 2021). 
Employee involvement, performance-oriented culture, and management commitment are the main organizational factors influencing the implementation of the performance measurement system (Hassan, Nordin, \& Azamin, 2021). There must be real cooperation between managers, controllers and employees (Bouamama, Basly, \& Zian, 2021). A strong involvement of the top management is required (Kaplan \& Norton, 2001) because it has the legitimacy to make the project of adoption and effective use of the balanced scorecard understood and accepted by all the actors, particularly in case of possible organizational rigidities (Bouamama, Basly, \& Zian, 2021).

2.2. Impact of Contingency Factors on Dashboard Content. Several research studies offer companies the opportunity to develop new performance measurement systems containing financial and non-financial information (Kaplan R., 2010; Bouamama, Basly, \& Zian, 2021). Researchers perceive the benefits of performance measurement systems for both public and private companies. Furthermore, they assert that the failure or success of the adoption process depends on various external and internal factors (Hassan, Nordin, \& Azamin, 2021). On the theoretical level, the application of contingency theory to the field of management control shows that the characteristics of management control systems can vary from one company to another depending on factors such as size, age, and industry (Rherib, El Amili, \& Baba El Khourchi, 2021; FrancoisXavier, Noe, \& Souaibou, 2021), as well as business strategy, environment, structure, management style, and others (Bouamama, Basly, \& Zian, 2021).

2.2.1. Internal Factors. Internal factors refer to those elements that constitute the firm's internal environment and are controllable by it. Despite this control, these elements can help or hinder the performance and climate of the company (Hassan, Nordin, \& Azamin, 2021). Internal characteristics represent a critical factor in the adoption of modern management control practices in various companies. In the literature, a set of internal elements are involved in numerous studies to determine whether there is an effect on the adoption of innovation and use of modern management practices, namely, the balanced scorecard (Hassan, Nordin, \& Azamin, 2021). In the case of Algerian economic enterprises, the organizational factors that affect the performance measurement system are explored.

a. Size: firm size is one of the most studied contingency factors in organization theory (Bouamama, Basly, \& Zian, 2021). The quantitative study conducted on French mid-sized companies shows that their balanced scorecards can be described as unbalanced. Financial managers in this type of company do not use, to the same extent, all the indicators that constitute the four dimensions of the balanced scorecard (Bouamama, Basly, \& Zian, 2021).

In contrast, Rherib, El Amili, and Baba El Khourchi argue that large companies have more sophisticated performance measurement systems and are more likely to have the balanced scorecard as a strategic steering tool (Rherib, El Amili, \& Baba El Khourchi, 2021). Other authors support the previous finding stating that the firm size incentivizes to follow balanced and forward-looking performance measures (Sharma \& Sharma, 2020). The larger the size, the more the company balances its performance measurement system to be consistent with the BSC structure (Costantini, Landi, \& Bonazzi, 2020). Company size has a positive and significant relationship with the balancing of company dashboards, especially with the level of use of customer indicators and organizational learning (Francois-Xavier, Noe, \& Souaibou, 2021).

Assumption. A: Company's size has a significant effect on the degree of balanced scorecard adoption (Costantini, Landi, \& Bonazzi, 2020; Sharma \& Sharma, 2020; Hassan, Nordin, \& Azamin, 2021; FrancoisXavier, Noe, \& Souaibou , 2021; Rherib, El Amili, \& Baba El Khourchi, 2021; Bouamama, Basly, \& Zian, 2021).

b. Age: as a second common factor; the firm age (Rherib, El Amili, \& Baba El Khourchi, 2021; FrancoisXavier, Noe, \& Souaibou , 2021). Due to higher management learning, older organizations are more likely to adopt management accounting techniques. It is expected to be higher in older firms applying these thoughts to the degree of adoption of the balanced scorecard (Rherib, El Amili, \& Baba El Khourchi, 2021). The quantitative study results based on the contingency factors and the development of indicators in public companies indicate that the relationship between age and the balance of the dashboards is not significant (Francois-Xavier, Noe, \& Souaibou, 2021). This finding is also confirmed by the research results of Rherib, El Amili, \& Baba El Khourchi (2021). Otherwise, age does not affect the variety and integration of balanced scorecard indicators (Francois-Xavier, Noe, \& Souaibou, 2021; Rherib, El Amili, \& Baba El Khourchi, 2021). However, this relationship remains significant between firm age and the degree of use of BSC organizational learning indicators (Francois-Xavier, Noe, \& Souaibou, 2021). 
Assumption. B: Company's age has a significant effect on the degree of balanced scorecard adoption ( Hassan, Nordin, \& Azamin, 2021; Francois-Xavier, Noe, \& Souaibou , 2021; Rherib, El Amili, \& Baba El Khourchi, 2021).

c. Strategy: the strategy type adopted is also considered as a contingency factor impacting balanced scorecard adoption (Hoang, Dinh, Tran, \& Nguy, 2018; Asiaei \& Bontis, 2019). Hoang, Dinh, Tran, and Nguy's findings distinguish between two types of strategies; cost dominance strategy and differentiation strategy. A differentiation orientation emphasizes using the non-financial perspectives of the balanced scorecard (Hoang, Dinh, Tran, \& Nguy, 2018). As a result, we can expect that companies pursuing a differentiation strategy are more likely to use the BSC approach than companies seeking a cost domination strategy. The differentiation strategy focuses on providing products or services that customers perceive as unique. These include superior quality, delivery, product design and flexibility (Hoang, Dinh, Tran, \& Nguy, 2018).

Assumption. C: Company's strategy has a significant effect on the degree of balanced scorecard adoption ( Hassan, Nordin, \& Azamin, 2021; Asiaei \& Bontis, 2019; Hoang, Dinh, Tran, \& Nguy, 2018).

d. Foreign Ownership: The authors find that foreign ownership is significantly and consistently related to the use of the balanced scorecard. Firms with significant foreign ownership in the ownership structure show a higher degree of use of this tool (Sharma \& Sharma, 2020).

Assumption. D: Foreign ownership of a company has a significant effect on the degree of balanced scorecard adoption (Sharma \& Sharma, 2020; Hassan, Nordin, \& Azamin, 2021; Asiaei \& Bontis, 2019).

e. Organizational Structure: two organizational structure characteristics are commonly used in the contingency literature (Hoang, Dinh, Tran, \& Nguy, 2018). These are mechanical and organic structures (Labadidi, Labadidi, Colak, \& Dayan, 2020). A mechanical structure involves centralized decision-making, strict adherence to formally prescribed rules and procedures, and carefully constructed roles and relationships, which, together, promote coordination, specialization, and efficiency. On the other hand, an organic structure is characterized by low specialization and formalization, facilitates decentralized decision-making, encourages flexibility, and emphasizes horizontal rather than vertical communication (Labadidi, Labadidi, Colak, \& Dayan, 2020). According to Hoang, Dinh, Tran, and Nguy (2018) and Sharma and Sharma (2020), the organizational structure is not significantly related to balanced scorecard use.

Assumption. E: Company's organizational structure has a significant effect on the degree of balanced scorecard adoption (Sharma \& Sharma, 2020; Hassan, Nordin, \& Azamin, 2021; Bouamama, Basly, \& Zian, 2021).

2.2.2. External Factors. External contingency factors refer to elements belonging to the company's external environment that are uncontrollable by it and affect the stability and process of its business (Hassan, Nordin, \& Azamin, 2021).

f. Environmental Uncertainty: perceived environmental uncertainty is one of the crucial contingent variables widely used in management accounting information research (Hoang, Dinh, Tran, \& Nguy, 2018). Environmental uncertainty drives the collection of sophisticated information to improve the decision-making process for managers. It plays a moderating role in the relationship between balanced scorecard implementation and business performance, which shows the value of collecting accurate and timely information about emerging conditions that interact with management systems (Bouamama, Basly, \& Zian, 2021). According to Sharma and Sharma (2020) and Bouamama, Basly, and Zian (2021), the environment does not seem to impact the adoption of BSCs. However, when the uncertainty of the environment is associated with the firm size, a significant and positive relationship is found. Large firms operating in an uncertain environment produce more balanced and diversified dashboards to cope with the complex and uncertain global environment (Bouamama, Basly, \& Zian, 2021).

Assumption. F: Environmental uncertainty has a significant effect on the degree of balanced scorecard adoption (Sharma \& Sharma, 2020; Hassan, Nordin, \& Azamin, 2021; Bouamama, Basly, \& Zian, 2021).

g. Competition Intensity: Hoang, Dinh, Tran, and Nguy reveal that competition level is the most important factor that can affect the balanced scorecard use. The rivalry intensity among competitors in a certain market refers to the extent to which companies in an industry pressure each other and limit their potential profit (Hoang, Dinh, Tran, \& Nguy, 2018).

Assumption. G: Competition intensity has a significant effect on the degree of balanced scorecard adoption (Sharma \& Sharma, 2020; Bouamama, Basly, \& Zian, 2021; Hassan, Nordin, \& Azamin, 2021). 


\section{Method and Data}

3.1. Method. Our research is based on a quantitative study to analyze the performance measurement practices by conducting a questionnaire. The survey is sent to 186 Algerian economic companies from different sectors. Only 57 responses were obtained, that 43 were complete and usable. Otherwise, we obtained a response rate of $23.12 \%$. These companies have different profiles and are distributed according to a set of well-defined criteria. These criteria are related to the contingency factors and their one-dimensional analysis. Sample firms were contacted through an online questionnaire (Bouamama, Basly, \& Zian, 2021; Rherib, El Amili, \& Baba El Khourchi, 2021). These companies are identified from two databases; the Algerian Chamber of Commerce and Industry containing 18,161 companies (CACI, s.d.) and Linkedin platform, where we targeted general managers, management controllers, auditors and financials. The selection of these respondent profiles is based on their roles in decision making as well as their knowledge of the management control characteristics of their entities (Amhalhal, Anchor, Papalexi, \& Dastgir, 2021). We were able to contact 186 companies. Only 57 responses were obtained in which 43 were complete and usable. Otherwise, we had a response rate of $23.12 \%$. Responses were obtained from public and private organizations operating in the manufacturing and service sectors, including telecommunications, banking, consulting and education, government institutes, and trade (Labadidi, Labadidi, Colak, \& Dayan, 2020), whether small, medium, or large, except for very small businesses (less than ten employees) (Amhalhal, Anchor, Papalexi, \& Dastgir, 2021) and associations.

The questionnaire consists mainly of closed-ended, dichotomous, and/or multiple-choice and scale questions. The questions are grouped into blocks according to the topic to which they refer. The different scales and the items composing the headings were first based on previous studies on the degree of balanced scorecards adoption (Bouamama, Basly, \& Zian, 2021). Three statistical steps were conducted to test our hypotheses. First, a univariate analysis to identify the respondents' and companies' profiles. Then, analyze our eight variables. Second, a bivariate analysis based on correlation studies to test the relationships between the variables. Finally, an explanatory analysis based on multiple regression to analyze the contingency factors effects on the degree of BSC adoption (Bouamama, Basly, \& Zian, 2021).

\subsection{Measurement Variables}

3.2.1. Dependent Variable. The dependent variable, namely "degree of use of balanced scorecard indicators", refers to the use of the BSC by the sample companies. It is measured by the degree of financial, customer, internal process, and learning and growth indicators (Kaplan \& Norton, 1992; Bouamama, Basly, \& Zian, 2021; Rherib, El Amili, \& Baba El Khourchi, 2021). A list of 14 measurement objectives was submitted for respondents to rate the degree of use of these measures. Based on a three-point Likert scale, respondents could choose whether they agreed or disagreed with a given statement or remain neutral (Benková, Gallo, Balogová, \& Nemec, 2020). The overall degree of use of the BSC indicators is the sum of its four dimensions scores. The higher the overall score of the four performance axes (out of 12 points), the more intense is the use of diversified performance indicators in the dashboard (Bouamama, Basly, \& Zian, 2021; Rherib, El Amili, \& Baba El Khourchi, 2021).

\subsubsection{Independent Variables}

\subsubsection{Internal Contingency Factors}

a. Size: To measure the firm size, we considered the firm's workforce. The workforce is grouped into four groups in which each group has a value attributed to it: (1) for "less than 50 employees", (2) for "50 to 100 employees", (3) for "100 to 200 employees", and (4) for "more than 200 employees" (Costantini, Landi, \& Bonazzi, 2020).

b. Age: This variable is measured by the number of years since the start of firm activity. Based on this data, companies are grouped into four main groups in which each group has a value attributed to it: (1) for "less than 5 years", (2) for "between 5 and 10 years", (3) for "between 10 and 15 years", and (4) for "more than 15 years".

c. Strategy: The Company's strategy is measured through three-point Likert scales (1: disagree, 2: neither agree nor disagree, 3: agree) that identify the type of strategy adopted by our sample companies; differentiation or cost domination strategy. We analysed this variable through the following elements: customer services, product offerings and cost reduction.

d. Foreign ownership: This variable is measured by a dichotomous question that takes the value 1 if the firm is owned by a multinational group and 2 if it is not. We also measured firm ownership from another angle where we addressed a single choice question with three modalities: public, private or mixed company. 
e. Organizational Structure: This independent variable is measured by the distribution of power and responsibilities (Bouamama, Basly, \& Zian, 2021) by asking single-choice questions to determine the type of structure, the management style, the actors included in the decision-making process and the direction of information flow within the firm. We will retain two categories of structures: centralized mechanistic and decentralized organic.

\subsubsection{External Contingency Factors}

f. Environmental Uncertainty: Perceived environmental uncertainty is measured by assessing the degree of environment dynamism (at both levels; economic and technological) and the degree of turbulence or predictability of competitors' actions and behaviours through three-point Likert scales (1: disagree, 2: neither agree nor disagree, 3: agree) (Bouamama, Basly, \& Zian, 2021).

g. Intensity of Competition: The second external factor is measured through a 5-point linear Likert scale, ranging from "1: very weak" to " 5 : very strong". The survey questions are carried over from previous researchers, with some slight modifications.

\section{Results}

4.1. Respondent Profiles. The first part of the survey aims to provide a brief demographic description of the respondent's profiles and the manufacturing and non-manufacturing firms participating in the study (Amhalhal, Anchor, Papalexi, \& Dastgir, 2021). Table 1 summarizes the general respondents characteristics (function and experience). The study sample is mainly composed of management controllers, Chief Executive Officers, auditors and financiers with a rate of $79.08 \%$ of the total respondents. It is essential to ensure that the participants occupy responsibility positions and have knowledge and experience of the organizational and environmental characteristics, and control practices used within their organizations (Amhalhal, Anchor, Papalexi, \& Dastgir, 2021). In addition, a large majority of our responded managers are moderately experienced; only about $28 \%$ have been in their current position for over 10 years.

Table 1. Frequency Distribution of Respondents' Characteristics

\begin{tabular}{|c|l|c|c|}
\hline \multicolumn{1}{|c|}{ Measure } & \multicolumn{1}{|c|}{ Items } & Frequency & Percentage \\
\hline \multirow{4}{*}{ Respondent status } & Chief Executive Officer & 10 & 23,3 \\
\cline { 2 - 4 } & Financial Director & 1 & 2,3 \\
\cline { 2 - 4 } & Financial Analyst & 5 & 11,6 \\
\cline { 2 - 4 } & Management controller & 14 & 32,6 \\
\cline { 2 - 4 } & Auditor, accountant & 4 & 9,3 \\
\cline { 2 - 4 } & Others & 4 & 20,9 \\
\cline { 2 - 4 } & Total & 43 & 100,0 \\
\hline \multirow{3}{*}{ Experience } & Less than one year & 10 & 23,3 \\
\cline { 2 - 4 } & One to 5 years & 14 & 32,3 \\
\cline { 2 - 4 } & From 5 to 10 years & 12 & 27,9 \\
\cline { 2 - 4 } & More than 10 years & 43 & 100,0 \\
\cline { 2 - 4 } & Total & & 23 \\
\hline
\end{tabular}

Source: Compiled by the authors

4.2. Company Profiles. Table 2 and Figures 1 and 2 below present the main characteristics of the responding firms. Most firms are privately owned (53.49\% of the sample). Only $34.88 \%$ of the responding firms are owned by multinationals (15 private and mixed enterprises).

Table 2. Frequency Distribution of Company Characteristics

\begin{tabular}{|c|l|c|c|}
\hline Measure & \multicolumn{1}{|c|}{ Items } & Frequency & Percentage \\
\hline \multirow{2}{*}{ Age } & Less than 5 years & 4 & 9,3 \\
\cline { 2 - 4 } & Between 10 and 15 years & 9 & 20,9 \\
\cline { 2 - 4 } & More than 15 years & 30 & 69,8 \\
\cline { 2 - 4 } & Total & 43 & 100,0 \\
\hline \multirow{2}{*}{ Size "employees' number" } & SME & 16 & 37,2 \\
\cline { 2 - 4 } & Large company & 27 & 62,8 \\
\hline \multirow{2}{*}{ Total } & & 43 & 100 \\
\hline \multirow{2}{*}{ Economic sector } & Primary & 13 & 30,2 \\
\cline { 2 - 4 } & Secondary & 22 & 51,2 \\
\cline { 2 - 4 } & Tertiary & 43 & 100 \\
\hline
\end{tabular}

Source: Compiled by the authors 


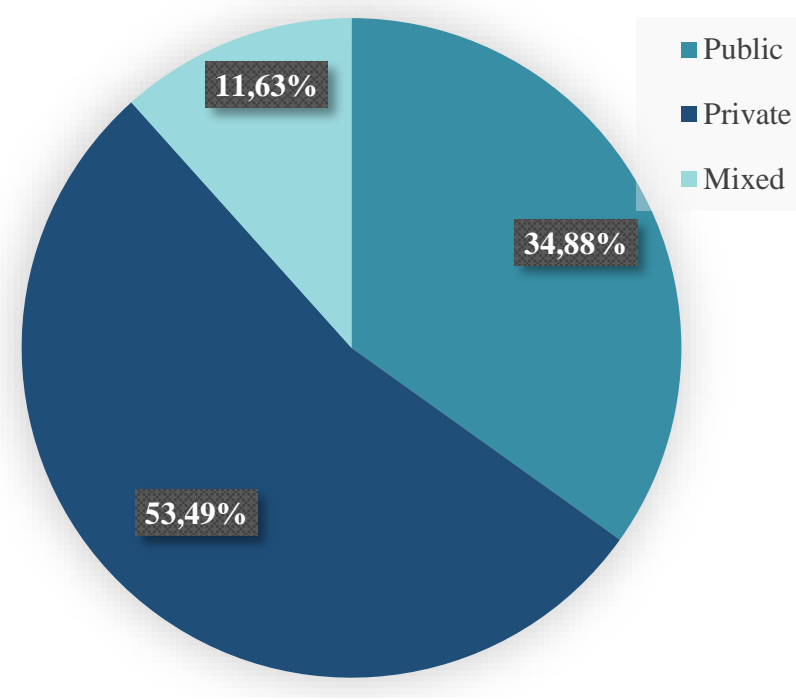

Figure 1. Distribution of Companies by Ownership

Source: Compiled by the authors

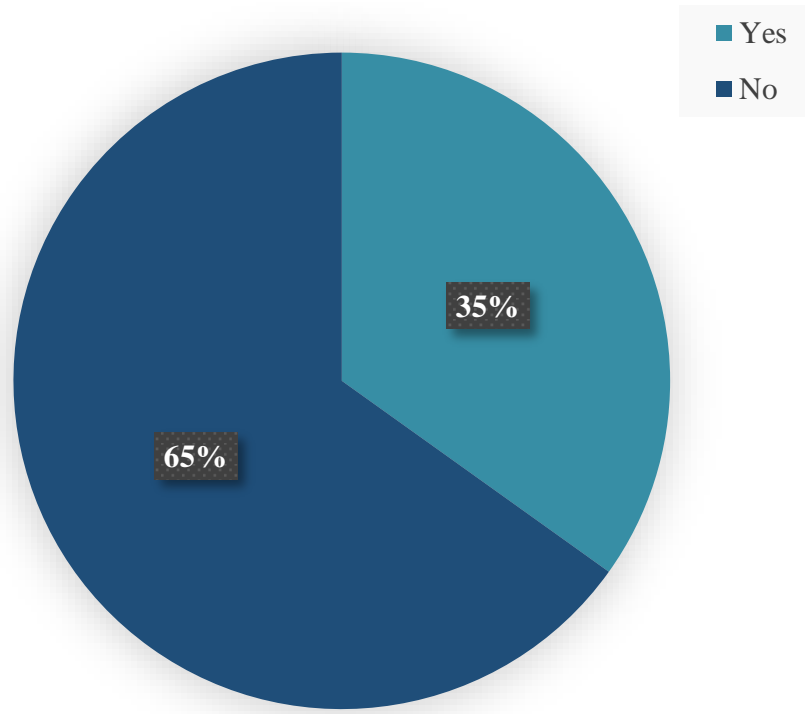

Figure 2. Company's Foreign Ownership

Source: Compiled by the authors

Nearly $63 \%$ of the sample are large firms, and $37.2 \%$ are small or medium-sized (Costantini, Landi, \& Bonazzi, 2020; Rherib, El Amili, \& Baba El Khourchi, 2021). We found that $69.8 \%$ of the sample companies have been established for more than 15 years. A company's age and seniority give us a vision of its ability to survive and its position in its life cycle. A critical or start-up phase of its activity. In terms of industry type (Table 2 and Figure 3). 51.2\% of sample companies operate in the tertiary economic sector, i.e., the service industry, such as banking companies with $20.93 \%$ and telecommunications companies with $11.63 \%$. The second most important economic sector is the secondary sector, with $30.2 \%$ combining construction and food industries. Finally comes the primary sector with $18.6 \%$ of the sample, of which $13.95 \%$ of companies operate in the sector of hydrocarbons, energy, and mining. 


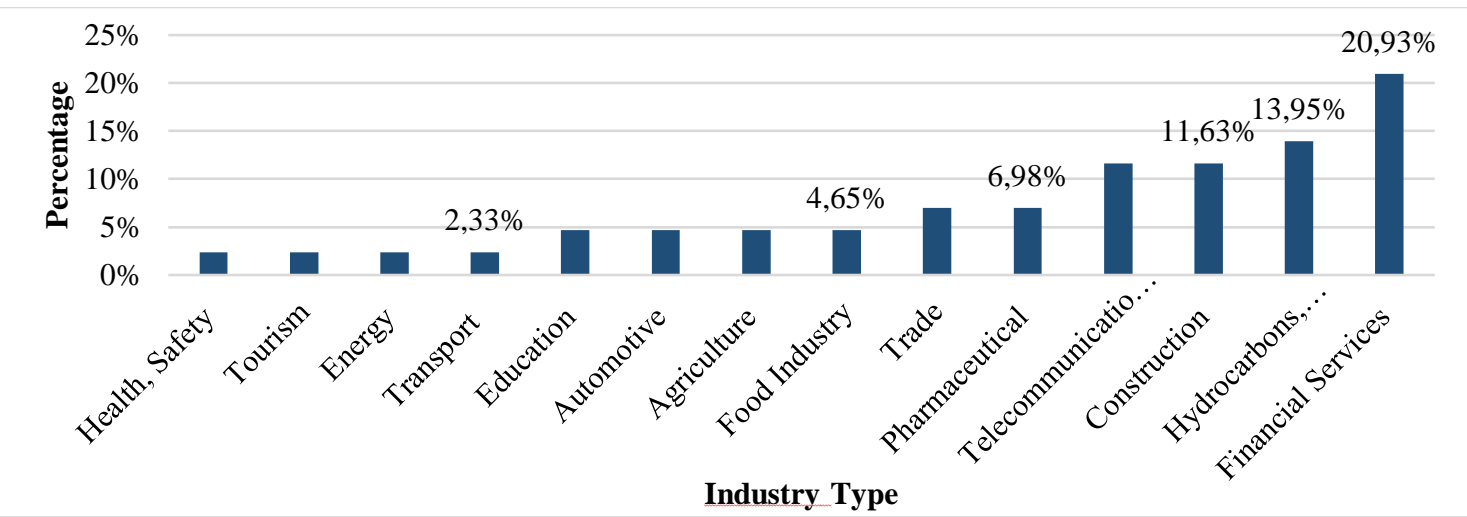

Figure 3. Distribution of Companies by Industry Type

Source: Compiled by the authors

4.3. Degree of Use of BSC Indicators. From table 3 we can observe that $55.8 \%$ of the companies do not use the balanced scorecard as a performance management tool.

Table 3. Description of balanced scorecard use

\begin{tabular}{|l|c|c|c|}
\hline Measure & Items & Frequency & $(\%)$ \\
\hline BSC use & Yes & 19 & 44,2 \\
\cline { 2 - 4 } & No & 24 & 55,8 \\
\cline { 2 - 5 } & Total & 43 & 100,0 \\
\hline
\end{tabular}

Source: Compiled by the authors

As Table 4 shows, $74.5 \%$ of companies use financial indicators in their performance measurement system, while $67.2 \%$ of companies highly use customer performance indicators. As for the degree of use of BSC indicators, Table 5 shows the average score for this variable. The results of Tables 4 and 5 show that financial managers and controllers of our economic enterprises do not equally use the four dimensions of the balanced scorecard. The BSCs implemented by the sample's companies are moderately balanced.

Table 4. Degree of Use of Financial and Non-Financial Indicators

\begin{tabular}{|c|c|c|c|c|}
\hline & \multicolumn{4}{|c|}{ \% of enterprises } \\
\hline $\begin{array}{c}\text { Degree of BSC use } \\
\text { (Indicators evaluated on 3 points) }\end{array}$ & $\begin{array}{c}\text { Financial } \\
\text { Indicators }\end{array}$ & $\begin{array}{c}\text { Customer } \\
\text { performance }\end{array}$ & $\begin{array}{c}\text { Internal } \\
\text { Processes }\end{array}$ & $\begin{array}{c}\text { Learning and } \\
\text { Growth }\end{array}$ \\
\hline Low & 4,7 & 14,0 & 7,0 & 11,7 \\
\hline Medium & 20,9 & 18,6 & 27,9 & 25,6 \\
\hline High & 74,5 & 67,2 & 65,1 & 62,8 \\
\hline Total & 100 & 100 & 100 & 100 \\
\hline
\end{tabular}

Source: Compiled by the authors

Furthermore, $65.1 \%$ of the respondents acknowledge having a high use of process indicators and then comes the learning and growth indicators by only $62.8 \%$ of the responses; it appears that these are lower than those concerning financial indicators.

Table 5. Average Scores of the Four Axes of the Balanced Scorecard

\begin{tabular}{|l|c|c|c|c|c|}
\hline \multicolumn{1}{|c|}{ Variables } & N & Min & Max & Mean & $\begin{array}{c}\text { Standard } \\
\text { deviation }\end{array}$ \\
\hline Degree of use of Financial Indicators & 43 & 1 & 3 & 2,68 &, 47114 \\
\hline Degree of use of Customer Indicators & 43 & 1 & 3 & 2,60 &, 53083 \\
\hline Degree of use of Internal Processes & 43 & 1 & 3 & 2,58 &, 51351 \\
\hline Degree of use of Learning and Growth Indicators & 43 & 1 & 3 & 2,50 &, 52135 \\
\hline Degree of use of BSC indicators & 43 & 4 & 12 & 10,36 & \\
\hline
\end{tabular}

Source: Compiled by the authors

Table 5 shows the average scores for the four performance areas. With an average score of 2.68 , financial indicators are the most used indicators. Customer performance and internal process indicators follow this. Finally, the overall average score for learning and growth indicators is the lowest (2.50). These indicators are therefore not widely used in the balanced scorecards of Algerian economic enterprises. It is confirmed by the fact that almost $37.3 \%$ of managers acknowledge using these indicators marginally (low or average use) (Table 4). To summarize, our sample's companies' most used performance measures relate to financial aspects, followed 
by customer performance aspects. In addition, learning and growth indicators have the lowest use in our enterprises' dashboards.

4.4. Strategy Type. The table below indicates the strategy type adopted by the studied companies, whether it is differentiation or cost domination strategy. The results of the same table show that the differentiation strategy is the most common one with $67.4 \%$ of the sample.

Table 6. Description of the Strategy Type Adopted by the Companies

\begin{tabular}{|l|l|c|c|}
\hline \multicolumn{1}{|c|}{ Items } & \multicolumn{1}{|c|}{$\mathbf{~ N ~}$} & $\mathbf{( \% )}$ \\
\hline \multirow{3}{*}{ Strategy type } & Differentiation & 29 & 67,4 \\
\cline { 2 - 5 } & Cost domination strategy & 14 & 32,6 \\
\cline { 2 - 5 } & Total & 43 & 100,0 \\
\hline
\end{tabular}

Source: Compiled by the authors

Table 7. Distribution of Companies by Strategy Type

\begin{tabular}{|c|c|c|c|c|}
\hline $\begin{array}{c}\text { Strategy type } \\
\text { (Indicators evaluated on 3 points) }\end{array}$ & \multicolumn{2}{c|}{ Cost domination } \\
\hline Degree & $\boldsymbol{N}$ & $\mathbf{( \% )}$ & $\boldsymbol{N}$ & $(\%)$ \\
\hline Low & 7 & 16,3 & 12 & 27,9 \\
\hline Medium & 11 & 25,6 & 14 & 32,6 \\
\hline High & 25 & 58,1 & 17 & 39,5 \\
\hline Total & 43 & 100 & 43 & 100 \\
\hline
\end{tabular}

Source: Compiled by the authors

According to Table 7, the differentiation strategy is strongly followed by our sample (58.1\%). Most companies provide quality products or services, respect delivery times and adapt them to customers' expectations to differentiate themselves from their competitors through the quality, availability and uniqueness of the products or services offered.

4.5. Organisational Structure. The following table (Table 8) indicates that more than half of the companies $(56.1 \%)$ adopt a centralized organizational structure following hierarchical or functional structures. The most common management style is directive or persuasive. In contrast, $43.9 \%$ of the companies follow a decentralized structure by adopting more autonomous and flexible organizations such as divisional structure, delegative and participative management styles. The results in the same table are also affected by the actors' involvement in the decision-making process and the information flow within the company. We note that decision-making is centralized in 53.5\% of companies and is mainly taken by the highest management level. The same applies to the information flow, where $74.4 \%$ of companies generally have a top-down approach.

Table 8. Description of the Organisational Structure Type

\begin{tabular}{|l|l|c|c|}
\hline \multicolumn{1}{|c|}{ Measure } & \multicolumn{1}{|c|}{ Items } & Frequency (n) & Percentage (\%) \\
\hline \multirow{5}{*}{ Sturcture type } & Centralised & 23 & 56,1 \\
\cline { 2 - 4 } & Decentralised & 18 & 43,9 \\
\cline { 2 - 4 } & Total & 41 (missing values = 2) & 100,0 \\
\hline \multirow{3}{*}{ Decision-making } & Centralised & 23 & 53,5 \\
\cline { 2 - 4 } & Decentralised & 20 & 46,5 \\
\cline { 2 - 4 } & Total & 43 & 100 \\
\hline \multirow{3}{*}{ Information flow } & Centralised & 32 & 74,4 \\
\cline { 2 - 4 } & Decentralised & 11 & 25,6 \\
\cline { 2 - 4 } & Total & 43 & 100 \\
\hline
\end{tabular}

Source: Compiled by the authors

\subsection{Environmental Uncertainty}

Table 9. Degree of Environmental Uncertainty

\begin{tabular}{|l|c|c|c|c|}
\hline $\begin{array}{c}\text { Environmental uncertainty } \\
\text { (Indicators evaluated on 3 points) }\end{array}$ & \multicolumn{2}{c|}{ Dynamism } & \multicolumn{2}{c|}{ Turbulence } \\
\hline Degree & \multicolumn{2}{|c|}{$\mathrm{n}(\%)$} & 11,7 & $\mathrm{n}(\%)$ \\
\hline Low & 5 & 44,2 & 20 & 25,6 \\
\hline Medium & 19 & 44,2 & 12 & 46,5 \\
\hline High & 19 & 100 & 43 & 28 \\
\hline Total & 43 & & \\
\hline
\end{tabular}

Source: Compiled by the authors 
According to the table above, the perceived environmental uncertainty (dynamism and turbulence), is considered medium to high by most respondents. Their companies operate in a changing, competitive, and threatening environment.

4.7. Competition Intensity. The degree of competition among the sample's companies is very strong or strong in $69.7 \%$ of them. By crossing industry with competition intensity, it was found that the financial and the oil and gas sector are more competitive than the other sectors mentioned above.

Table 10. Degree of Companies' Competition

\begin{tabular}{|c|c|c|c|c|}
\hline $\begin{array}{c}\text { Competition intensity } \\
\text { (Indicators evaluated on 5 points) }\end{array}$ & $\begin{array}{c}\text { Frequency } \\
\text { (n) }\end{array}$ & Percentage (\%) & Mean & Standard deviation \\
\hline Very low & 2 & 4,7 & 3,93 & 1,142 \\
\hline Low & 3 & 7,0 & & \\
\hline Neither low nor not low & 8 & 18,6 & & \\
\hline Strong & 13 & 30,2 & & \\
\hline Very strong & 17 & 39,5 & & \\
\hline Total & 43 & 100 & & \\
\hline
\end{tabular}

Source: Compiled by the authors

4.8. Results of the Bivariate Analysis. To test the relationships between the two main groups of contingency factors and the balanced scorecard adoption, correlations between our seven explanatory variables (internal variables: size, age, strategy, foreign ownership, organizational structure; external variables: environmental uncertainty and competitive intensity) and the four axes of the balanced scorecard are therefore calculated (Bouamama, Basly, \& Zian, 2021). Table 11 summarizes the results of the correlation analysis (PEARSON's correlation coefficient), which seeks to measure the direction and strength (Bouamama, Basly, \& Zian, 2021) that exist between our pairs of dependent and independent variables. Size, age, strategy type, competition and uncertainty of the environment have a significant relationship with the balanced scorecard indicators' diversity. In contrast, company ownership and type of organizational structure have no impact on adopting various indicators. For differentiation strategy, it appears to be positively correlated with all four types of BSC indicators. It should be noted that this relationship is very strong for customer indicators $(r=0.795 ; p<0.01)$, followed by internal process indicators $(r=0.528 ; p<0.01)$, which are non-financial indicators.

Therefore, although the managers interviewed use financial indicators more frequently (Table 5), differentiation strategy tends to push them to use non-financial indicators more often. We can explain these results through the questionnaire answers. They show that companies that adopt a differentiation strategy tend to present favourable services and product offers for their customers (reducing and respecting delivery times, improving work processes, presenting quality products and ensuring their availability, meeting customers' expectations, etc.). Moreover, the strategy of cost dominance is also positively correlated with three types of balanced scorecard indicators and shows no relationship with the learning and growth indicators $(r=0.282 ; p>$ 0.05). It can be explained by the lack of investment in infrastructure and human capital development, which are sources of appropriation of competitive advantage. The relationship between age and BSC adoption is significant. Age is positively correlated with three types of BSC indicators; financial indicators $(r=0.333 ; p>0.05)$, internal processes $(r=0.325 ; p>0.05)$ and learning and growth $(r=0.330 ; p>0.05)$. The older the company, the more likely it is to use financial, internal process and organizational learning indicators. However, age does not seem to affect the adoption of customer indicators.

Table 11. Correlation Results Between Contingency Factors and Use of BSC Indicators

\begin{tabular}{|l|c|c|c|c|c|}
\hline & & \multicolumn{4}{|c|}{ Degree of BSC } \\
\hline & Contingency factors & $\begin{array}{c}\text { Financial } \\
\text { Indicators }\end{array}$ & $\begin{array}{c}\text { Customer } \\
\text { Performance }\end{array}$ & $\begin{array}{c}\text { Internal } \\
\text { processes }\end{array}$ & $\begin{array}{c}\text { Learning and } \\
\text { Growth }\end{array}$ \\
\hline & Size & $0,301^{*}$ & 0,121 & 0,262 & 0,037 \\
\hline & Age & $0,333^{*}$ & 0,265 & $0,325^{*}$ & $0,330^{*}$ \\
\hline & Foreign ownership & $-0,150$ & 0,037 & $-0,176$ & $-0,105$ \\
\hline \multirow{2}{*}{\begin{tabular}{c} 
Strategy \\
\cline { 2 - 6 }
\end{tabular}} & $\begin{array}{c}\text { Organizational } \\
\text { structure }\end{array}$ & 0,146 & 0,218 & 0,078 & 0,096 \\
\hline \multirow{2}{*}{$\begin{array}{l}\text { Environmental } \\
\text { uncertainty }\end{array}$} & Differentiation & $0,480^{* *}$ & $0,795^{* *}$ & $0,528^{* *}$ & $0,477^{* *}$ \\
\hline & Cost dominance & $0,333^{*}$ & $0,500^{* *}$ & $0,441^{*}$ & 0,282 \\
\cline { 2 - 6 } & Dynamism & 0,218 & $0,351^{*}$ & $0,314^{*}$ & $0,365^{*}$ \\
\hline
\end{tabular}

Notes: *Coefficient is significant at 0.05 level; $* *$ Coefficient is significant at 0.01 level

Source: Compiled by the authors 
In addition, competition intensity has a very strong positive relationship $(0.5<r<1)$ with the dependent variable. The strongest correlation is between competition intensity and customer indicators $(r=0.760 ; p<0.01)$. The implementation of the balanced BSC indicators increases with the company's product/service diversity and when the level of competition in the market is high. Environmental uncertainty appears to have a positive average linear relationship with the four indicator dimensions $(0<r<0.5)$. A fairly close relationship is found regarding the degree of environmental dynamism since the results show that this contingency factor is significantly correlated with three of the four BSC indicators: customer performance, internal processes, learning, and growth, which are again non-financial indicators. Companies in such an environment tend to change their marketing practices frequently and adopt new technologies to meet new needs and remain competitive. Turbulence is positively correlated with two indicators; internal processes $(r=0.353 ; \mathrm{p}<0.05)$ and financial $(r=0.309 ; p<0.05)$ (Table 11). On the one hand, companies operating in a turbulent environment fluctuate their sales volumes annually to increase market share and brand awareness. On the other hand, they reduce costs and improve work efficiency to increase profits.

According to Table 11, company size has no significant impact on the degree of customer indicators' integration, internal process indicators and learning and growth indicators $(p>0.05)$. These variables are independent of the company size, whether it is small, medium or large. In contrast, the degree of integration of financial indicators variable has a significant relationship with the company size $(r=0.301 ; p<0.05)$. Therefore, the larger the size of the company, the more it tends to balance its dashboards by integrating financial indicators. These results demonstrate the importance of the presence of financial information in our sample, such as having measures indicating return on capital employed. Finally, contrary to our expectations, the company's foreign ownership as well as the type of organisational structure seem to have no significant relationship with the degree of use of the four BSC indicators, $(p>0.05)$. Therefore, the influence of these variables on the variety of BSC indicators is not established.

4.9. Correlation Matrix. A correlation matrix and the VIF indices are presented in Table 12. The correlation matrix does not show strong correlations between all explanatory variables. However, in the same table we find significant correlation relationships between 8 pairs of variables. According to that table, competition intensity appears to have positive and significant relationships with three other variables. The first strongest correlation is observed with differentiation strategy $(r=0.941 ; p<0.05)$. This correlation is both strong $(r$ is very close to 1) and positive. This implies that the more intense the competition, the more firms adopt a differentiation strategy and vice versa. The second strongest correlation is observed between competition intensity and environmental uncertainty $(r=0.574 ; p<0.05)$. The more the environment is uncertain, turbulent and dynamic, the more the rivalry between competitors becomes intense and vice versa. Then, comes competition intensity and cost dominance strategy who have a positive and significant relationship $(r=0.542$; $p<0.05)$.

Differentiation strategy also has positively significant relationships with three other explanatory variables. The first combination is with intensity of competition who is already discussed. The second significant combination is with cost dominance strategy. They have a positive linear relationship $(r=0.470 ; p<0.05)$. Firms can differentiate themselves from competition by either adopting a top-down differentiation strategy, i.e., presenting higher quality products/services at a higher price or they adopt a bottom-up differentiation strategy, which implies a less comprehensive but low-cost offer. The latter one is compatible with strategy of cost domination. Third, we have the differentiation strategy who has a positive and significant relationship with environmental uncertainty $(r=0.415 ; p<0.05)$.

We also cite the relationships of environmental uncertainty with cost dominance strategy and foreign ownership. Environmental uncertainty has a significant relationship with cost dominance strategy $(r=0.277 ; p<0.05)$. The last pair of variables (uncertainty and foreign ownership) has a negative linear relationship $(r=-0.381 ; p<0.01)$. A company belonging to a multinational group implies operating in a global market that is characterised by complexity, uncertainty and threatening, unpredictable and new environmental changes. The negative relationship means that the more uncertain the environment is, the more companies are limited to local or known markets. Finally, age has a positive and average linear relationship with both cost dominance strategy $(r=0.349 ; p<0.05)$ and firm size $(r=0.385 ; p<0.05)$. Furthermore, since all VIF (Variance Inflation Factor) values are less than 1.8 , multicollinearity is not a problem in our regression model.

Table 12 also shows significant correlation relationships between some of the explanatory variables and the degree of use of the four axes of the balanced scorecard. The strongest positive correlations $(+0.5<r<+1)$ are observed between competition intensity, differentiation strategy and the dependent variable at a value of $(r=0.748 ; p<0.01)$ and $(r=0.691 ; p<0.01)$. The positive and average linear relationship $(0<r<+0.5)$ is 
also found between cost dominance strategy $(r=0.471 ; p<0.01)$, environmental uncertainty $(r=0.444 ; p<0.01)$, size $(r=0.377 ; p<0.01)$ and the degree of use of the balanced scorecard indicators. To test the influence of contingency factors on degree of use of balanced scorecard indicators, a multiple regression is conducted. In our model, $\mathrm{R}^{2}=0.645$, adjusted $\mathrm{R}^{2}=0.608$ which means that the explanatory variables explain $64.5 \%$ of the dependent variable (total variance), namely, the degree of use of the balanced scorecard indicators. Furthermore, we have $F(4.38)=17.27 ; p<0.001$. We can conclude that our regression model is highly significant. The results of the regression analysis are presented in Table 12.

Table 12. Correlation Matrix

\begin{tabular}{|l|c|c|c|c|c|c|c|c|c|c|}
\hline \multicolumn{1}{|c|}{ Variables } & $\mathbf{1}$ & $\mathbf{2}$ & $\mathbf{3}$ & $\mathbf{4}$ & $\mathbf{5}$ & $\mathbf{6}$ & $\mathbf{7}$ & $\mathbf{8}$ & $\mathbf{9}$ & VIF \\
\hline $\begin{array}{l}\text { 1. Degree of use of BSC } \\
\text { indicators }\end{array}$ & 1.000 & & & & & & & & & \\
\hline 2.Size & 0.214 & 1.000 & & & & & & & & - \\
\hline 3.Age & $0.377^{*}$ & $0.385^{*}$ & 1.000 & & & & & & & 1.072 \\
\hline 4.Foreign ownership & -0.116 & -0.160 & -0.072 & 1.000 & & & & & & - \\
\hline 5.Differentiation strategy & $0.691^{* *}$ & 0.009 & 0.225 & -0.063 & 1.000 & & & & & 1.003 \\
\hline 6.Cost dominance strategy & $0.471^{* *}$ & 0.026 & $0.349^{*}$ & -0.129 & $0.470^{* *}$ & 1.000 & & & & \\
\hline 7. Organizational structure & -0.123 & 0.195 & 0.229 & 0.103 & -0.129 & -0.082 & 1.000 & & & - \\
\hline 8.Environmental uncertainty & $0.444^{* *}$ & 0.062 & 0.206 & $-0.381^{*}$ & $0.415^{* *}$ & $0.277^{* *}$ & 0.083 & 1.000 & & 1.504 \\
\hline 9.Competition intensity & $0.748^{* *}$ & 0.034 & 0.242 & -0.140 & $0.941^{* *}$ & $0.542^{* *}$ & 0.188 & $0.574^{* *}$ & 1.00 & 1.529 \\
\hline
\end{tabular}

Notes: *Coefficient is significant at 0.05 level; ** Coefficient is significant at 0.01 level

Source: Compiled by the authors

4.10. Multiple Regression Results. According to the results of the previous bivariate analysis, size, foreign ownership and organisational structure do not seem to have an impact on the degree of use of balanced scorecard indicators and are therefore excluded from the regression analysis. From the four explanatory variables retained in the multiple regression model (Table 13), only age, strategy and competitive intensity are significant $(p<0.05)$. Contrary to our expectations, environment uncertainty does not have a significant impact on the degree of use of BSC indicators.

Table 13. Regression Model (Degree of Use of BSC Indicators)

\begin{tabular}{|l|c|c|c|c|}
\hline \multicolumn{1}{|c|}{ Explanatory variables } & $\boldsymbol{\beta}$ (Beta) Coefficients & & Student t & Sig \\
\hline $\mathrm{R}$ & & 0,803 & & \\
\hline $\mathrm{R}^{2}$ ajusté & & 0,645 & & \\
\hline $\mathrm{R}^{2}$ & & 0,608 & & \\
\hline Erreur standard de l'estimation & & 0,26455 & & \\
\hline Constant & & & 2,370 & 0,023 \\
\hline Age & 0,217 & & 2,168 & $0,036^{* *}$ \\
\hline Strategy & $-0,213$ & & $-2,199$ & $0,034^{* *}$ \\
\hline Environmental uncertainty & 0,008 & & 0,067 & 0,947 \\
\hline Competition intensity & 0,692 & & 5,793 & $0,000^{*}$ \\
\hline$n=43$ & & & & \\
\hline
\end{tabular}

Notes: *Coefficient is significant at 0.001 level; ** Coefficient is significant at 0.05 level

Source: Compiled by the authors

The results show that the factor with the most substantial effect $(\beta=0.692)$ is competition intensity. It has a positive impact on the degree of use of the BSC indicators $(t=5.793 ; p<0.001)$, i.e., firms operating in a highly competitive environment are likely to use the four balanced scorecard performance indicators more effectively and in a more balanced manner. According to Hoang, Dinh, Tran, and Nguy (2018), BSC companies operate in competitive markets and face strong competitive pressure. Company age has the second strongest effect on the degree of balanced scorecard adoption $(\beta=0.217)$. However, this effect is negligible. The older the company, the more it seeks to balance its scorecards. Finally, differentiation strategy has a weak and negative impact on the dependent variable $(\beta=-0.213)$. On the other hand, unexpectedly, we found no support for the hypothesized relationship between environmental uncertainty and the degree of use of balanced scorecard indicators according to correlation matrix results (Table 12). Therefore, environmental uncertainty does not influence our dependent variable.

\section{Discussion}

This research responds to the literature calls for further analysis of the impact of contingency factors on the degree of balanced scorecards adoption (Bouamama, Basly, \& Zian, 2021). Our results show the existence of causal relationships between specific factors related to the internal context of the firm: size, age, foreign 
ownership, strategy and organizational structure and certain external factors: uncertainty of the environment and intensity of competition. According to the results of Bouamama, Basly and Zian (2021), François-Xavier, Noe and Souaibou (2021), Rherib, El Amili and Baba El Khourchi (2021), we found that the use of financial indicators is dominant in the balanced scorecards of our Algerian economic enterprises. Customer and internal process indicators are used to a lesser extent. However, the learning and growth dimension is the least used by these same companies. Although the balanced scorecard is one of the most effective tools in the management control and performance measurement field (Costantini, Landi, \& Bonazzi, 2020), 55.8\% of our sample's companies do not use this tool. These results are consistent with previous research of the same authors, which shows a relatively low use of the balanced scorecard. The percentage of companies that have adopted the BSC as a business management tool in this survey is $44.2 \%$ (Table 13), which, without being particularly negative, is lower in less developed countries (Ibid.).

Using correlation analysis, we found a positive effect of three internal contingency factors (initially five factors) on the diversity of the balanced scorecard indicators: size, age, and strategy type (differentiation and cost domination). As for the external factors, environmental uncertainty and competition intensity are also significantly related to the multi-dimensionality of the BSC indicators. The positive and significant effect of size on the variety of balanced scorecard indicators is also observed in the studies of François-Xavier, Noe and Souaibou (2021) and Rherib, El Amili and Baba El Khourchi (2021). It is interesting to note that, in our analyses, this relationship is significant only with financial indicators, contrary to the results of the previous authors, which show that there is a meaningful relationship between size and the other three non-financial indicators of the balanced scorecard, i.e., customer performance, internal processes and learning and growth.

Furthermore, enterprise age is significantly correlated with three types of indicators (financial, internal processes, learning and growth), contrary to the findings of François-Xavier, Noe and Souaibou (2021) and Rherib, El Amili and Baba El Khourchi (2021) who state that there is no significant relationship between the firm age and the use of diversified indicators. Differentiation strategy is positively related to all axes of the balanced scorecard. A powerful correlation of this factor is observed with customer indicators. Contrary to Bouamama, Basly and Zian (2021) results, foreign ownership and organizational structure do not seem to impact the four BSC axes' use significantly. These results are partly in line with our first and third hypotheses (H.a. and H.c.) concerning the impact of internal contingency factors on the use of BSC indicators $(60 \%$ of the overall rate of the five internal factors).

Environmental uncertainty is moderately significant with the use of the four indicators of the balanced scorecard. This result is different from that of Bouamama, Basly and Zian (2021), who find that this variable impact on the variety of indicators used in the BSC is not established (Bouamama, Basly, \& Zian, 2021). In our case, competition intensity is highly significant with the degree of use of the four types of indicators. These results are consistent with our second hypothesis, which indicates the significant impact between external factors and the degree of use of the balanced scorecard indicators. The results of the correlation matrix state that age, the two strategy types (differentiation and cost dominance), the environment uncertainty, and the competition intensity are significantly related to the degree of use of the balanced scorecard. While size, foreign ownership and organizational structure are not. These results are in line with those of Hoang, Dinh, Tran and Nguy (2018), in terms of a significant relationship between differentiation strategy, environmental uncertainty, competition intensity and the degree of BSC use and, those of Bouamama, Basly and Zian (2021), in terms of differentiation strategy only.

However, the decentralized structure seems to be significantly correlated with the degree of balanced scorecard adoption in the studies of the same others (Hoang, Dinh, Tran, \& Nguy, 2018; Bouamama, Basly, \& Zian, 2021), which is not the case for our results. Contrary to our results and those of Bouamama, Basly and Zian (2021), the company size seems to have a significant correlation with the integration of the four axes of the balanced scorecard, the studies of Sharma and Sharma (2020), Costantini, Landi, and Bonazzi (2020), Rherib, El Amili, and Baba El Khourchi (2021), and François-Xavier, Noe, and Souaibou (2021), conclude that the larger the size of the company, the more balanced are its scorecards (Sharma \& Sharma, 2020; Costantini, Landi, \& Bonazzi, 2020; Rherib, El Amili, \& Baba El Khourchi, 2021; Francois-Xavier, Noe, \& Souaibou , 2021). For enterprise age, it has a significant relationship with the degree of use of the balanced scorecard indicators. This finding is inconsistent with the results generally obtained in management control by Rherib, El Amili and Baba El Khourchi (2021) and by François-Xavier, Noe and Souaibou (2021). Finally, the result stating that foreign ownership is not correlated with the use of the balanced scorecard is contrary to the results of Sharma and Sharma (2020). Otherwise, Algerian firms whose foreign capital has a considerable importance in the ownership structure show a lower degree of balanced scorecard use and therefore, may not cohere and match the management and control system of the foreign parent entity (Sharma \& Sharma, 2020). 
Furthermore, through multiple regression analyses, which are more appropriate for testing our hypotheses (Sharma \& Sharma, 2020), and despite the numerous relationships between several factors and the dependent variable concluded in the correlation analysis, age, competition intensity, and differentiation strategy remain the only factors that are significantly associated with the degree of use of balanced scorecard indicators. In this context, Kaplan and Norton argued that the balanced scorecard approach is more appropriate when the level of competition in the market is high and when the adoption of differentiation strategy and age are greater (Hoang, Dinh, Tran, \& Nguy, 2018). This finding is consistent with the results of Hoang, Dinh, Tran and Nguy (2018). The more competition is intense (competitive markets and facing highly competitive pressure), also, the more strategy has a differentiation orientation, the more companies tend to use multidimensional indicators related to the balanced scorecard (Ibid.). This result is consistent with the hypothesis stating that companies adapt their balanced scorecards to the degree of competition.

However, our regression model shows no impact of environmental uncertainty on the degree of balanced scorecard adoption (Table 13). This result is also consistent with the empirical study of Bouamama, Basly and Zian (2021), but inadequate with that of Hoang, Dinh, Tran and Nguy (2018). This result rejects our sixth hypothesis (H.f.) stating that companies adapt their balanced scorecards to the degree of environment uncertainty. After obtaining our results from the correlation analysis as well as the multiple regression analysis and after discussing and comparing them with the results of the literature review, we can therefore reject or validate our seven research hypotheses. The validation of the pre-established model is presented in Table 14.

Table 14. Validation Model

\begin{tabular}{|c|c|c|c|c|}
\hline Factors & \multirow{8}{*}{ 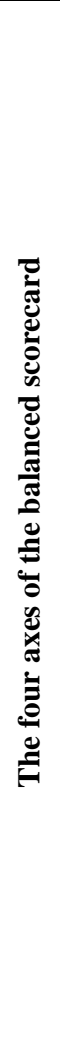 } & \multirow{4}{*}{$\begin{array}{l}\text { Financial } \\
\text { Indicators }\end{array}$} & Hypothèses & Validation \\
\hline a. Age & & & $\begin{array}{l}\text { H.a. Age has a significant effect } \\
\text { on the degree of adoption of the } \\
\text { balanced scorecard }\end{array}$ & Validated \\
\hline b. Size & & & $\begin{array}{l}\text { H.b. Size has a significant effect } \\
\text { on the degree of adoption of the } \\
\text { balanced scorecard }\end{array}$ & Rejected \\
\hline c. Strategy & & & $\begin{array}{l}\text { H.c. Strategy has a significant } \\
\text { effect on the degree of adoption } \\
\text { of the balanced scorecard }\end{array}$ & Validated \\
\hline d. Foreign ownership & & \multirow{2}{*}{$\begin{array}{l}\text { Customer } \\
\text { Indicators }\end{array}$} & $\begin{array}{l}\text { H.d. Foreign ownership has } \\
\text { asignificant effect on the degree } \\
\text { of adoption of the balanced } \\
\text { scorecard }\end{array}$ & Rejected \\
\hline e. Organisational structure & & & $\begin{array}{l}\text { H.e Organisational structure has } \\
\text { a significant effect on the degree } \\
\text { of adoption of the balanced } \\
\text { scorecard }\end{array}$ & Rejected \\
\hline f. Environment uncertainty & & \multirow[t]{2}{*}{$\begin{array}{l}\text { Internal Process } \\
\text { Indicators }\end{array}$} & $\begin{array}{l}\text { H.f. Environment uncertainty } \\
\text { has a significant effect on the } \\
\text { degree of adoption of the } \\
\text { balanced scorecard }\end{array}$ & Rejected \\
\hline g. Competition intensity & & & $\begin{array}{l}\text { H.g. Competition intensity has a } \\
\text { significant effect on the degree } \\
\text { of adoption of the balanced } \\
\text { scorecard }\end{array}$ & Validated \\
\hline
\end{tabular}

Source: Compiled by the authors

\section{Conclusion}

In the Algerian context, our research measures the degree of the balanced scorecard adoption impacted by a set of environmental and organizational contingency factors. It was found that nearly $56 \%$ of the studied companies do not have a balanced scorecard. Otherwise, the performance measurement systems of Algerian economic enterprises are still based on traditional (financial) measures despite the turbulence of their economic environment and the competition intensity. Financial managers and controllers of these companies do not often use diversified and multidimensional indicators or measures in their management control practices. A Balanced Scorecard is an integrative approach to managing organizations' performance (Makhloufi, Sadaoui, \& Badi, 2021). An integrative approach seeks to translate the company's strategy and strategic objectives into operational objectives (Mamabolo \& Kerrin, 2020). According to the study results, Algerian economic enterprises do not use the value of this innovative balanced scorecard approach. It can be explained by the culture that circulates in the environment of Algerian companies, especially their internal environment. 
According to the study's participants, their firms generally follow a centralized mechanistic structure. They have hierarchical or functional organizations characterized by bureaucracy, rigidity and poor information flow between stakeholders. Their most common management styles are directive or persuasive management. The sole involvement of senior management in the decision-making process, the slow of information flow between all organisational levels and the minimal focus on intangible assets and human capital development are contrary to the characteristics of comprehensive strategic management which tends to link strategic decisions to operational activities. Also, the correlation study's results show the existence of significant relationships of four contingency factors: age, company strategy, competition intensity and environmental uncertainty. Then, multiple regression allowed us to go further in our analysis and it is concluded that only three factors impact the degree of BSC adoption. These factors are age, differentiation strategy and competitive intensity.

Thus, we conclude that the balanced scorecard adoption increases with (1) the rivalry of firms in their markets, (2) the degree of diversity of products and services offered and, (3) the oldest and most mature firms are the most likely to use this tool. Our model is limited by excluding the effects of other essential contingency factors, such as organizational culture, corporate social responsibility, industry, computerization and others. However, limiting ourselves to a single country allows us to control the effects of local management practices. Also, we provide evidence of associations rather than concluding causality. Another limitation is the low representativeness of the sample, which may generate a bias risk. Despite this study's limitations, the main findings have potential implications for future research, particularly for researchers wishing to test the diversity in the use of the balanced scorecard across different industries and to explore its advantages and disadvantages.

Author Contributions: Conceptualization: Sara Aicha Amrani, Mehdi Bouchetara; data curation: Sara Aicha Amrani, Mehdi Bouchetara; formal analysis: Sara Aicha Amrani, Mehdi Bouchetara; investigation: Sara Aicha Amrani, Mehdi Bouchetara; methodology: Sara Aicha Amrani, Mehdi Bouchetara., Sidi Mohammed Bouchenak Khelladi; project administration: Mehdi Bouchetara; resources: Sara Aicha Amrani, Mehdi Bouchetara, Messaoud Zerouti; software: Messaoud Zerouti, Sara Aicha Amrani, Mehdi Bouchetara; supervision: Mehdi Bouchetara, Messaoud Zerouti, Sidi Mohammed Bouchenak Khelladi; validation: Mehdi Bouchetara, Messaoud Zerouti, Sidi Mohammed Bouchenak Khelladi, Nabil Mehddeb; visualization: Mehdi Bouchetara; writing - original draft: Sara Aicha Amrani, Mehdi Bouchetara; writing - review \& editing: Sara Aicha Amrani, Mehdi Bouchetara.

Funding. There is no funding for this research.

\section{References}

1. Alibelhadj, Y. (2019). Application of Algerian Companies of Balanced Scorecard Performance Model for Good Governance. Journal of Financial, Accounting and Managerial Studies, 13(2), 16-24. Available at: [Link]

2. Ali-Belhadj, Y., \& Benhabib, A. (2018). Factors Influencing the Use of the Balanced Scorecard Performance Model by Algerian Companies. Les Cahiers du MECAS, 14(1), 42-51. [Google Scholar]

3. Amhalhal, A., Anchor, J., Papalexi, M., \& Dastgir, S. (2021). Organisational performance and the use of multiple performance measures in an emerging market. International Journal of Quality \& Reliability Management. [Google Scholar] [CrossRef]

4. Asiaei, K., \& Bontis, N. (2019). Using a balanced scorecard to manage corporate social responsability. Knowledge and Process Management, 26(4), 371-379. [Google Scholar] [CrossRef]

5. Benková, E., Gallo, P., Balogová, B., \& Nemec, J. (2020). Factors Affecting the Use of Balanced Scorecard in Measuring Company Performance. Sustainability, 12(3), 1178. [Google Scholar] [CrossRef]

6. Bescos, P.-L., Deville, A., \& Foulquier, P. (2020). BSC and long-term deployment: an actors' perspective. Journal of Applied Accounting Reaserch, 21(3), 383-396. [Google Scholar] [CrossRef]

7. Bouamama, M., Basly, S., \& Zian, H. (2021). How do contingency factors influence the content of balancced scorecards? An empirical study of French inermediate-size entreprises. Journal of Accounting \& Organizational Change, 17(3), 373-393. [Google Scholar] [CrossRef]

8. CACI. (n.d.). Algerian Chamber of Commerce and Industry: directory of Algerian companies. Available at: [Link]

9. Costantini, A., Landi, S., \& Bonazzi, M. (2020). Factors Influencing the use of the Balanced Scorecard: Evidence from a Regional Context in Italy. International Journal of Academic Research in Business and Social Sciences, 10(2), 578-596. [Google Scholar] [CrossRef]

10.Dudic, Z., Dudic, B., Gregus, M., Novackova, D., \& Djakovic, I. (2020). The Innovativness and Usage of the Balanced Scorecard Model in the SMPs. Sustainibility, 12(8), 3221. [Google Scholar] [CrossRef] 
11.Francois-Xavier, M., Noe, N., \& Souaibou, S. (2021). The Development Of Steering Indicators In Public Entreprises In Cameroon: An Implementation Based On Contengency Factors. Journal of Contemporary Issues in Business and Government, 1283-1300. Available at: [Link]

12.Hassan, A., Nordin, N., \& Azamin, A. (2021). The Influence of Organizational Culture and the External and Internal Factors on Performance Measurement System Adoption: A Conceptual Framework. Asian Journal of Interdisciplinary Reaserch, 101 -110. [Google Scholar] [CrossRef]

13.Hassani, R., \& Derahmoune, H. (2020). The Balanced Scorecard's contribution to the company's performance. Journal of The New Economy, 12(2), 264-278. [Google Scholar]

14.Hoang, V., Dinh, H., Tran, M., \& Nguy, T. (2018). Determinants Influencing the Usage of Balanced Scorecard for Performance Measurement: THE CASE OF VIETNAM. Academy of Accounting and Financial Studies Journal, 22(6), 1-15. [Google Scholar]

15.Kaplan, R. (2010). Conceptual Foundations of the Balanced Scorecard. Harvard Business School Working Papers. Available at: [Link]

16.Kaplan, R., \& Norton, D. (1992). The Balanced Scorecard: Measures That Drive Performance. Harvard Business Review, 71-79. [Google Scholar]

17.Kaplan, R., \& Norton, D. (1993). Putting the Balanced Scorecard to Work. Harvard Business Review, 1-16. [Google Scholar]

18.Kaplan, R., \& Norton, D. (1996). The Balanced Scorecard: translating strategy into action. United States of America: President and Fellows of Harvard College. Harvard Business Review Press; 1st edition (September 1, 1996), ISBN-10: 9780875846514

19.Kaplan, R., \& Norton, D. (2001). Transforming the Balanced Scorecard from Performance Measurment to Strategic Management. Accounting Horizons, 147-160. [Google Scholar]

20.Kaplan, R., \& Norton, D. (2007). Using the Blanced Scorecard as a Strategic Management System. Harvard Business Review, 1-14. [Google Scholar]

21.Labadidi, H.C., Labadidi, R., Colak, M., \& Dayan, M. (2020). Contingency effects of firm structure and environmental uncertainty on strategic planning process and firm performance: Evidence from UAE enterprises. Strategic Change, 29(2), 241-252. [Google Scholar]

22.Li, H., An, N., \& Liu, J. (2021). Strategic planning, strategy map and management control: a case study. Nankai Business Review International, 12(3), 386-408. [Google Scholar] [CrossRef]

23.Makhloufi, T., Sadaoui, F., \& Badi, A. (2021). The Implementation of the Management dashboard according to the OVAR Approach: Case of SONATRACH. Algerian Scientific Journal Platform, 12(1), 813-827. [Google Scholar]

24.Mamabolo, A., \& Kerrin, M. (2020). Performance Measurement in Emerging Market Social Enterprises using a Balanced Scorecard. Journal of Social Entrepreneurship, 11(1), 65-87. [Google Scholar] [CrossRef]

25.Moura, L.F. (2020). Factors for performance measurement systems design in nonprofit organizations and public administration. Measuring Business Excellence, 24(3), 377-399. [Google Scholar] [CrossRef]

26.Nimpa, A., \& Teulon, F. (2018). Point of view: an exploratory study of the applicability of the Balanced Scorecard in SMEs in French-speaking sub-Saharan Africa. Gestion 2000, 35(3), 129-143. [Google Scholar] [CrossRef]

27.Rherib, N., El Amili, O., \& Baba El Khourchi (2021). The impact of company size and age on Balanced Scorecard adoption in Morocco: Results of an empirical study. International Review of Management Sciences, 4(2), 671-685. [Google Scholar]

28. Sharma, D., \& Sharma, U. (2020). Analysis of balanced scorecard usage by private companies. Pacific Accounting Review, 33(1), 36-63. [Google Scholar] [CrossRef] 